\title{
Chapter 16 Approval Voting in Germany: Description of a Field Experiment
}

\author{
Carlos Alós-Ferrer and Đura-Georg Granić
}

\subsection{Introduction}

The 2008 state elections in the German state of Hesse were expected to be extremely close. However, nobody expected that forming a new government would reveal itself to be impossible and, after long months of unsuccessful attempts, new elections would have to be called for almost exactly 1 year later.

On the original election day, January 21 st 2008, we carried out a field experiment on approval voting in the German town of Messel, with the explicit permission and friendly support of the Hessian Ministry for the Interior and for Sport, the head election organizer (Mr. Wolfgang Hannappel), the mayor of the Messel district (Mr. Udo Henke), and the election commissioner (Mr. Dieter Lehr). This collaboration allowed us to install separate voting booths in each of the three different voting areas in the Messel district. Voters had been previously contacted per post and asked to take part in a secondary hypothetical vote after casting their official vote. In this second vote, Approval Voting was offered as an alternative voting system.

Our motivation was twofold. First, we were inspired by the experiment of Laslier and Van der Straeten $(2004,2008)^{1}$ in the French Presidential Elections of 2002 and wanted to conduct an analogous study in Germany. We believe that conducting such field experiments in different countries is crucial to establish the practical applicability of the method. ${ }^{2}$ Second, the particularities of the German electoral system allowed us to conduct two simultaneous experiments with the same voters, one where Approval Voting was used to select a candidate under a winner-take-all procedure (as in previous experiments elsewhere), and one where votes were cast

\footnotetext{
${ }^{1}$ See also Laslier (2006).

${ }^{2}$ The bottom-line motivation, as in Laslier and Van der Straeten (2004, 2008) or Brams and Fishburn (2005), is to show that Approval Voting could readily be incorporated into the political process. The desirability of such a development is founded on the method's sound theoretical properties, as shown by Brams and Fishburn (1978) and made explicit by the characterization results of Fishburn (1978a, 1978b) and Alós-Ferrer (2006).

C. Alós-Ferrer $(\varangle)$

Department of Economics, University of Konstanz, Box 150, D-78457 Konstanz, Germany e-mail: Carlos.Alos-Ferrer@uni-konstanz.de
} 
for political parties rather than candidates, with an ensuing proportional system to determine representation in the (state) parliament.

Indeed, most German state elections are idiosyncratic in that voters are asked to cast two different votes. The first, for the district election ("Wahlkreisstimme") is given to a named candidate, and the results are determined by the winner-takes-all procedure with simple majority. Half the seats in the state parliament are allocated through this method (direct seats). The second vote, for the state election ("Landesstimme"), determines the percentage of the total seats (not the remaining ones) to be allocated to each different party which reaches at least $5 \%$ of the votes. ${ }^{3}$ Hence, although approval voting is typically considered for candidate elections only, it was natural, in our setting, to ask voters to provide approval ballots both for district candidates and for state parties. ${ }^{4}$

Before the election, we sent a letter to the 3,017 citizens of Messel who were eligible to vote. ${ }^{5}$ This letter explained the experiment's objective and the way it would be carried out. Additionally, the letter was published in the local city hall bulletin. To the best of our knowledge, ours is the first field experiment to try out this method in Germany.

As mentioned above, the main purpose of the investigation was to contribute to the empirical testing of Approval Voting. We were particularly interested in examining any differences between the outcomes of the hypothetical vote and the voting system currently in use. The results brought additional insights for political and economic theory as well as understanding the (rather delicate) political situation in Hesse.

We asked the voters in Messel to fill out two different voting forms: one for the district election and another for the state election. Thus we had two different sources of data. For the electoral district vote, there was a relatively small number of candidates ( 8 in total) to choose from. For the state election, there was a relatively large number of parties (17 in total).

\subsection{The Official Election}

Messel is part of the hessian electoral district 51 (Darmstadt-Dieburg). There were eight candidates in this district for the district elections, each representing one of the major parties: the CDU (conservative), the SPD (socialist), the Greens, the FDP (liberal), the Republicans (extreme right), the Left (extreme left), the Free Voters (mostly concerned with local issues), and the NPD (extreme right). The candidate

\footnotetext{
${ }^{3}$ There are minor complications if a party manages to capture a larger number of direct seats than the total percentage would allow it to have, or if a party which does not reach the $5 \%$ barrier obtains some direct seats. These difficulties are essentially dealt with by increasing the number of seats in parliament.

${ }^{4}$ This raises a number of interesting theoretical considerations. See Alós-Ferrer and Granić (2010) for a discussion.

${ }^{5}$ To preserve voter anonymity beyond all doubt, we provided the election officials with the letters and they were the ones to attach address labels and actually send them.
} 
for the SPD Party won the direct seat. In the state election, there were 17 different parties from which to choose: the CDU, the SPD, the Greens, the FDP, the Republicans, the Animal Protection Party, the Civil Liberties Party, the PSG (communist), the Popular Vote Party, the Grey Party (oriented towards senior citizen issues), the Left, the Violet Party (oriented towards spiritual issues), the Family Party, the Free Voters, the NPD, the 'Hessian Pirates' (an organization of computer hackers) and the UB Party ('Independent Citizen Politics').

The SPD and the CDU received the greatest percentage of the vote statewide, with roughly equal numbers of votes for each party. However, none of the traditional coalitions (CDU + FDP and SPD + the Greens) could reach an absolute majority. Only five parties received more than $5 \%$ of the vote, enabling them to sit in the state parliament. These were the CDU, the SPD, the FDP, the Greens and the Left. This pattern was also found in Messel, with the exception that the Left Party received only $4.9 \%$ of the vote and thereby just missed out the State Parliament barrier. This difference is statistically meaningless.

The 3,017 registered voters were divided among three voting stations: Messel I, Messel II and 'Grube Messel', with 1,326, 1,401 and 290 eligible voters respectively. On the election day, 1,909 voters took part personally in the official election (Messel I: 847, Messel II: 902, Grube Messel: 160). Additionally, 282 voters cast an absentee vote through the post. Thus a total of 2,191 voters voted in the election. This represented $72.6 \%$ of the eligible voting population, which is relatively high in comparison to other electorates. The participation figures were similar to those for previous elections in Messel. This supports the notion that the (announced) experiment had no negative effects on voter participation.

\subsection{The Experiment}

Only people who voted at the voting stations took part in our experiment. Thus the absentee voters are not included in the data for this experiment. Of the 1,909 voters, $967(50.65 \%)$ took part in the study (Messel I: 461, 54.43\% of voters; Messel II: 407, 45.12\% of voters; Grube Messel: 99, 66.88\% of voters). There were 6 invalid votes in total (4 in Messel I, 2 in Messel II). ${ }^{6}$ Our sample is thus composed of a total of 961 voters (Messel I: 457; Messel II: 405; Grube Messel: 99).

The results of both the district and state elections differ from those of the official election. These differences are especially pronounced in the official election. Here we will present a descriptive summary of our results, structured in four different sections ${ }^{7}$ : the District vote; the State Vote; a hypothetical 'Messel-State Parliament'; and further miscellaneous observations (for example, Coalition results).

\footnotetext{
${ }^{6}$ It is of course quite hard to cast an invalid vote under approval voting. These six voters wrote comments on the ballot instead of using it for voting. One of them actually stapled a long declaration on the political situation in Messel to the ballot.

${ }^{7}$ A more detailed analysis is presented in Alós-Ferrer and Granić (2010) where, among other topics, we tackle the spatial representation of the Messel electorate's preferences using the spatial method described in Laslier (2006).
} 
Remark 16.3.1. Although the results in Messel in previous elections were representative of the results in the whole state of Hesse, it is of course not statistically possible to use our sample for making predictions about future political outcomes in the whole of Hesse. Our discussion is for this reason to be understood purely as informative. We limit our comparisons with the results of the official election in Messel itself.

Our tables are set out as follows:

- Candidate/Party: Name of the Candidate or Party.

- Votes: percentage of the voters who voted for (approved of) the Candidate/Party. Because every voter could vote for more than one Candidate/Party, the percentage does not add up to $100 \%$ but rather to $186 \%$ for the district election and $225 \%$ for the state election.

- Vote share: amount of votes (approvals) for a Candidate/Party, divided by the total number of votes (this represents a renormalization of the votes, so that they sum to $100 \%$ ).

- Z-Rank: The candidates and parties are arranged according to the size of their share of the votes in the hypothetical election (for example, the candidate with the most votes receives Z-Rank ' 1 ').

- Official Vote: Share of the votes in the official vote in Messel (excluding absentee votes).

- O-Rank: The candidates and parties are arranged according to the size of their share of the votes in the official election (for example, the candidate with the most votes receives O-Rank ' 1 ').

\subsubsection{District Election}

The following table summarizes the results of the district election, where voters had to elect a single candidate:

\begin{tabular}{lccccc}
\hline Candidate & Votes (\%) & Z-Share (\%) & Z-Rank & $\begin{array}{l}\text { Official } \\
\text { Election }(\%)\end{array}$ & O-Rank \\
\hline Hofmann, SPD & 58.0 & 31.2 & 1 & 45.9 & 1 \\
Milde, CDU & 41.8 & 22.5 & 2 & 37.9 & 2 \\
Harth, the Greens & 31.4 & 16.9 & 3 & 4.5 & 4 \\
Dr. Krug, FDP & 30.3 & 16.3 & 4 & 6.0 & 3 \\
Deistler, the Left & 10.4 & 5.6 & 5 & 3.4 & 5 \\
Herrmann, the & 7.4 & 4.0 & 6 & 0.8 & 7 \\
$\quad$ Free Voters & & & & & \\
Bauer, REP & 3.9 & 2.1 & 7 & 1.1 & 6 \\
Zeuner, NPD & 2.8 & 1.5 & 8 & 0.3 & 8 \\
Total & 186.0 & 100.0 & & 100.0 & \\
\hline
\end{tabular}


The salient features of the table are described below:

1. The winner, according to the Approval Voting method, would have been Mrs Hofmann (SPD), just as in the official election. The results of the Approval Voting method differ from those of the official election in that according to the Approval Voting method, Mrs Hofmann would have achieved an absolute majority. $58 \%$ of voters gave her their approval in the hypothetical ballot. This information is lost in the official election results.

2. The Approval Voting method alters the ranking of the different candidates. In the official election, the greens are ranked fourth and the FDP's candidate is ranked third. Their positions are actually swapped through the Approval Voting method.

3. In the official election, the candidate for the extreme-right Republicans is in sixth place, whilst the candidate for the Free Voter Party is in seventh place. This ranking is reversed in the results of the Approval Voting method. In this particular case, the difference between the two election methods is especially large. Whilst in the Approval Voting results the candidate for the Free Voter Party can count on a not insignificant percentage support of $7.4 \%$, in the official election he received only $0.8 \%$ of the total vote. The Republican candidate received a comparatively small percentage of the vote in the Approval Voting results, with $3.9 \%$ of the vote.

4. The voters voted for, on average, 1.86 candidates (standard-deviation: 0.874 ). This value is robust, as shown by the similar averages in the three different voting stations (Messel I: 1.89, Messel II: 1.83, Grube Messel: 1.84).

\subsubsection{State Election}

The following table summarizes the results for the State Election, where voters were asked to select a party list:

\begin{tabular}{lccccc}
\hline Party & $\begin{array}{c}\text { Votes } \\
(\%)\end{array}$ & $\begin{array}{c}\text { Z-Share } \\
(\%)\end{array}$ & Z-Rank & $\begin{array}{l}\text { Official } \\
\text { Election }(\%)\end{array}$ & O-Rank \\
\hline SPD & 53.8 & 23.9 & 1 & 38.9 & 1 \\
CDU & 44.6 & 19.8 & 2 & 36.0 & 2 \\
The greens & 36.1 & 16.0 & 3 & 7.0 & 4 \\
FDP & 32.6 & 14.5 & 4 & 9.0 & 3 \\
The left & 12.3 & 5.5 & 5 & 4.9 & 5 \\
Animal protection & 9.6 & 4.3 & 6 & 0.8 & 7 \\
$\quad$ party & & & & & \\
The family party & 9.6 & 4.3 & 6 & 0.2 & 12 \\
The free voters & 7.1 & 3.1 & 8 & 0.5 & 9 \\
Rebublican party & 3.3 & 1.5 & 9 & 1.0 & 6 \\
The popular vote & 2.9 & 1.3 & 10 & 0.2 & 13 \\
\hline
\end{tabular}




\begin{tabular}{lrrccc}
\hline Party & $\begin{array}{c}\text { Votes } \\
(\%)\end{array}$ & $\begin{array}{c}\text { Z-Share } \\
(\%)\end{array}$ & Z-Rank & $\begin{array}{l}\text { Official } \\
\text { Election }(\%)\end{array}$ & O-Rank \\
\hline NPD & 2.8 & 1.2 & 11 & 0.8 & 7 \\
The hessian pirates & 2.8 & 1.2 & 11 & 0.3 & 10 \\
The grey party & 2.5 & 1.1 & 13 & 0.2 & 13 \\
UB & 2.1 & 0.9 & 14 & 0.1 & 15 \\
The violet party & 1.0 & 0.5 & 15 & 0.3 & 11 \\
PSG & 0.9 & 0.4 & 16 & 0.1 & 15 \\
Civil liberties party & 0.9 & 0.4 & 16 & 0.1 & 15 \\
Total & 225.0 & 100.0 & & 100.0 & \\
\hline
\end{tabular}

Several interesting conclusions can be drawn from this table:

1. With the Approval Voting System, the notion of the 'two big parties' seems less appropriate to describe the political situation. There were in fact 4 parties which received an approval rate above 30\%: the CDU, the SPD, the Greens and the FDP. On this basis, the results of a state election (see 'Messel-Parliament' below) would have produced four major factions, each with a similar number of seats in Parliament. One could even infer on this basis, that the official vote's splitting of voter preferences into two political sides is an artificial product of the voting system. Parties such as the Greens and the FDP would have gained a great advantage through the Approval Voting system.

2. In Messel, according to the hypothetical election, the SPD Party received an absolute majority of the vote. Of course, under Approval voting it can be the case that more than one party receives an absolute majority. However, the SPD was the only such party in Messel.

3. Some of the parties that are categorized as 'small' become much larger with the Approval Voting system. There were three parties which in the official election received only a small percentage of the vote, and whose size grew to significantly more than 5\% of the vote with the Approval Voting method. The following parties showed such an increase: the Animal Protection Party (9.6\%), the Family Party (9.6\%) and the Free Voters (7.1\%). If we assume, with a leap of faith, that these figures are representative of the state of Hesse, then one can argue that these parties should have seats in the state Parliament (see the hypothetical 'MesselParliament' below).

4. The positions of the political minorities is distorted by the official voting method. After the four major parties and the Left come the Republicans (ranked sixth) and the NPD (ranked seventh). According to the Approval Voting system, however, it is the Animal Protection Party, the Family Party and the Free Voters who have the largest share of the votes after the four major parties and the Left (see above).

5. The voters voted on average for 2.25 parties (standard deviation: 1.141). This value remained robust, as the average value for the three voting stations was comparable (Messel I: 2.31, Messel II: 2.20, Grube Messel: 2.20). 
It is interesting to note that the Approval Voting system altered the notion of a two-party dominant system, showing instead four parties with a significant proportion of the vote. Additionally, certain so-called 'small parties' were seen to be significantly larger in the Approval Voting system than in the official system. The reasons for these differences can be clarified as follows. Because voters each voted on average for 2.25 parties, every party receives on average 2.25 times the number of votes that they would have received in the official election. This means that the number of votes for an 'average' party in the Approval Voting system, on the basis of their votes in the official election, is obtained by multiplying the number of votes in the official election by 2.25. For the CDU and the SPD however, this factor was only 1.24 and 1.38 respectively. In contrast, the Greens and the FDP received a factor of 5.14 and 3.62 respectively. The factors for the NPD and the Republicans were higher than average, with 3.5 and 3.3 respectively. But the factors for the Animal Protection Party, the Family Party and the Free Voter Party were enormously high, with $12.0,48.0$ and 14.2 respectively.

We draw the conclusion that the current official voting method presents a distorted view of voter opinions. This method forces the voter to decide for only one party. For many voters in this situation, the notion of 'making your vote count' would be very important. According to this argument, the small parties the voters would actually prefer to vote for, are ignored, because they are small and have no chance of winning, either at the local or state level. Instead, voters believe they should give their vote to one of the larger parties, whose positions the voter generally agrees with, although they are not as appealing to the voter as those of the preferred smaller party. In this way, the 'small' parties remain small, even when a significant proportion of the voting population sympathizes with them. For example, the CDU and SPD could possibly be chosen because they are large parties, although the preferences of the voters for the FDP and the Greens are just as marked. In this way, the large parties remain large, only because they are already large, and are seen as such.

A similar argument holds for the minority parties. Because of the drive to 'make your vote count' ('only vote for someone who has a chance of winning'), many 'small' parties are deprived of votes, because they are small at this point in time (although according to the real preferences of the voters, they should not really be so small). Because the Approval Voting system allows the voter with these preferences to choose the small party and the larger one, the notion of 'making your vote count' is no longer relevant, and it no longer influences the voting behaviour of the voter.

The argument for 'making your vote count' does not apply so well for protest voters and for voters who strongly disagree with all of the large parties. The official voting method here leads to parties on the far ends of the political spectrum being overvalued. With the Approval Voting system, these parties receive votes only from confirmed followers of the party, whilst other small parties (with less extreme political positions, such as the Animal Protection Party, the Family Party and the Free Voters; see the results above), freed from the constrictions of 'making your vote count', find comparably broader support. 


\subsubsection{The Messel Parliament}

In order to illustrate the way in which the application of the Approval Voting Method would change the composition of the state parliament, we constructed a hypothetical parliament, using the results of the approval vote in Messel. This is based on the assumption that the results for Messel are generalizable across the whole state. This hypothetical 'Messel-Parliament' is of course only intended to function as an illustrative picture of the potential effects of the Approval Voting method.

To enable a proper comparison, we first constructed a 'Messel-Parliament' on the basis of the official election results. That is, that we calculated the distribution of seats in the state Parliament of Hesse, by projecting the official election results onto the whole state.

The parliamentary election results, according to the official elections in Messel, look quite similar to the actual parliamentary election results for the entire state of Hesse. The only major difference is that the Left Party, with $4.9 \%$ in Messel, fell just short of the $5 \%$ lower limit. The actual statewide results showed, however, that the Left Party, with $5 \%$ of the vote, managed to get a place in the Hessian State Parliament. In order not to have this statistically irrelevant difference blur the overall picture, we have calculated the Messel-Parliament based on the assumption that $4.9 \%$ of the vote is good enough to gain a place in the Hessian Parliament.

The following table, and Fig. 16.1, show the hypothetical 'Messel-Parliament' according to the official election of the district of Messel. The distribution of seats is, as in the results of the official 2008 election, calculated according to the largest remainder method, known in Germany as the Hare-Niemeyer method. In this case, all parties that fell under the 5\% lower limit (in our case $4.9 \%$ ) were eliminated. The vote percentages were then recalculated on the basis of the total number of votes of the remaining parties. These results were multiplied by 110/100 (because there are 110 seats in the Hessian Parliament) and then rounded off. In accordance with the Hare-Niemeyer Rule, the remaining seats were allocated to the Parties with the largest remainders (counting from the first decimal place).

\begin{tabular}{lrcc}
\hline Party & Votes & \% (converted) & Mandates \\
\hline SPD & 726 & 40.65 & 45 \\
CDU & 671 & 37.57 & 41 \\
FDP & 168 & 9.41 & 10 \\
The Greens & 130 & 7.28 & 8 \\
The Left & 91 & 5.10 & 6 \\
Total & 1,786 & 100.00 & 110 \\
\hline
\end{tabular}

The picture is qualitatively similar to the actual distribution of seats in the actual hessian Parliament. The official election results for the whole state of Hesse show the following patterns: (1) the CDU and the SPD are the two major parties; 


\section{Parliament Messel (Official Vote)}

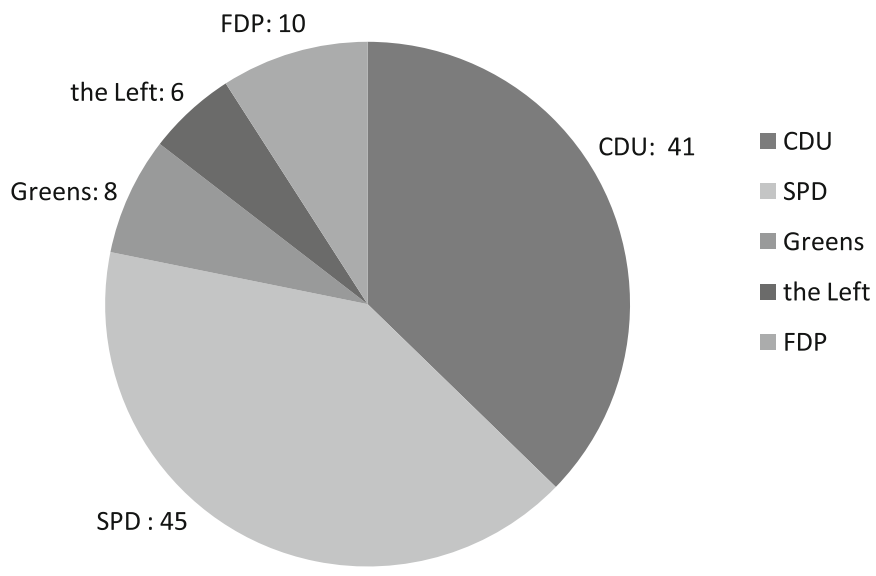

Fig. 16.1 The 'Messel Parliament', based upon the results of the official voting method

(2) neither of the "standard" coalitions, CDU + FDP and SPD + the Greens, could reach an absolute majority; and (3) the so-called 'big coalition' (CDU + SPD) would have had an absolute majority.

In order to create a hypothetical 'Messel-Parliament' from the Approval Voting data, we used a normalized voting-share. The number of approvals for the party, divided by the sum of all approvals for all parties (not through the number of voters) become the critical quantity to determine the number of elected members of any given party. To ensure a comparable distribution of our Messel-Parliament' we followed the official method of seat distribution as closely as possible. To do this, we used the Hare-Niemeyer method and maintained a 5\% lower limit for election to the hessian Parliament. In this case we must decide if the 5\% lower limit will be determined by votes or from vote-share. We decided that our criteria for election to the hessian Parliament would be determined by percentage of votes. This means that every party who received approvals from at least $5 \%$ of the voters, receives at least one seat in the hypothetical parliament. This procedure seemed both the simplest and most representative. ${ }^{8}$

The following table, and Fig. 16.2, show the hypothetical 'Messel-Parliament' as determined by the Approval Voting method. First, all parties which fell under the 5\% lower limit were eliminated. Subsequently, the vote-share for the remaining parties was calculated. These results were multiplied by the factor of 110/100 (because there are 110 seats in the hessian Parliament) and rounded off. The remaining seats were divided amongst the parties with the largest remainders.

\footnotetext{
${ }^{8}$ See Alós-Ferrer and Granić (2010) for details.
} 


\begin{tabular}{lrccc}
\hline Party & Votes & $\%$ (Votes) & Z-Share $(\%)$ & Mandates \\
\hline SPD & 517 & 53.8 & 26.16 & 29 \\
CDU & 429 & 44.6 & 21.71 & 24 \\
The greens & 347 & 36.1 & 17.56 & 19 \\
FDP & 313 & 32.6 & 15.84 & 17 \\
The left & 118 & 12.3 & 5.97 & 7 \\
Animal protection party & 92 & 9.6 & 4.66 & 5 \\
Family & 92 & 9.6 & 4.66 & 5 \\
The free voters & 68 & 7.1 & 3.44 & 4 \\
Total & 1,976 & 205.7 & 100.00 & 110 \\
\hline
\end{tabular}

\section{Parliament Messel (Approval Voting)}

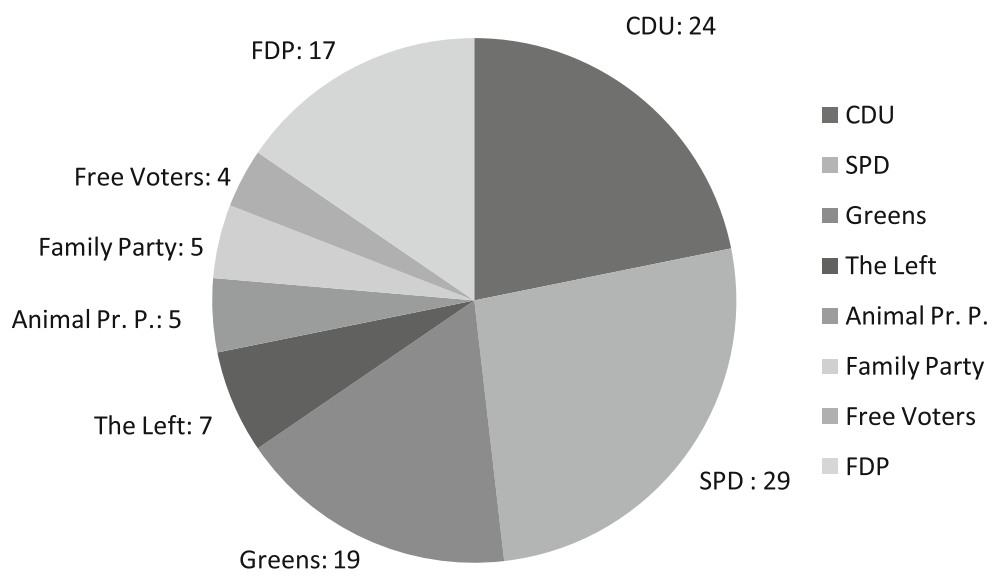

Fig. 16.2 The 'Messel Parliament', based upon the results of the Approval Voting data

The Messel Parliament based upon the results of the hypothetical voting method produced results that were quite different from those of the official state Elections: (1) according to the Messel Parliament, the majority of the seats would have been given to four different parties, the CDU, the SPD, the FDP and the Greens; (2) three small parties, which did not get any seats in the actual election, would have been elected to parliament in the hypothetical election: the Animal Protection Party, the Family Party and the Free Voters; and (3) the big coalition (the CDU and the SPD) would not have reached an absolute majority.

This hypothetical Messel Parliament allows some interesting possibilities for government formation. For example, the three new small parties in the Parliament (the Animal Protection Party, the Family Party and the Free Voters) together, could 
enable an SPD and Green Government, without the support of the Left or the FDP. ${ }^{9}$ On the other hand, these three small parties would not enable the formation of a CDU and FDP government. Even a wide coalition of all parties excluding the CDU and the SPD would be theoretically possible.

\begin{tabular}{lc}
\hline Coalition & Votes (\%) \\
\hline SPD + Greens & 27.68 \\
CDU + FDP & 25.18 \\
SPD + FDP & 9.47 \\
Big Coalition (CDU + SPD) & 9.16 \\
FDP + Greens & 6.14 \\
SPD + Green + The Left & 5.10 \\
'Jamaica' (CDU + FDP + Greens) & 4.99 \\
'Traffic light' (SPD + Greens + FDP) & 4.79 \\
\hline
\end{tabular}

\subsubsection{Further Remarks}

\subsubsection{Coalitions}

An advantage of the Approval Voting Method is that the popular support for a given coalition can be assessed through the different votes, without the necessity of an additional questioning of the electorate. The data set from our study allows us to calculate how many voters voted for a given coalition. The following table shows the number of voters who voted for the different potentially interesting coalitions.

From these results it can be seen that, in our data sample, there is only a small amount of voter support for the coalition groups that actually exist.

Other specific questions can also be easily answered. For example, 517 voters voted for the SPD whilst 118 voted for the Left. Out of these only 91 voters voted both for the SPD and the Left. That means that only $17.6 \%$ of SPD voters would also vote for the Left if they had the option of doing so. In contrast, $77.1 \%$ of voters who voted for the Left would also vote for the SPD.

\subsubsection{Number of Votes}

Previous studies (such as Laslier and Van Straeten's in Orsay, France) have reported that for the Approval Voting Method, the voters choose on average three candidates to vote for. This observation seems not to generalize to our results. In our Study,

\footnotetext{
${ }^{9}$ We would like to remark that the impossibility of an SPD + Green government without the support of neither the FDP nor the Left was the essence of the long government formation crisis in Hesse which lasted the whole year 2008 and eventually resulted in new elections in 2009.
} 
the voters chose on average 1.86 candidates (from 8 possible candidates) and 2.25 parties (from 17 possible parties). Because these average values were quite stable across the three different voting Stations in the district of Messel, we infer that the smaller number of candidates or parties voted for is the result of some as yet not identified psychological or cultural factor (one possible, purely economic explanation is that our participants had to provide two sets of data rather than only one, thereby opportunity costs of participating in the experiment were higher). The fact remains that the German voters in Messel 2008 chose significantly fewer from the potential options as the French voters in Orsay 2002.

\subsubsection{Visibility of the Small Parties}

Our study brought into focus another characteristic of the official voting system. All of the so-called 'small' parties face the problem of having low visibility. A significant number of voters speaking to us on polling day said that they never 'look down' far on the list of parties on the ballot paper. In other words, many voters took part in the official election without having read through the whole list of parties that they might vote for. When these voters came to the hypothetical vote, and had the possibility to vote for more than one party, the voters read the list all the way through. Some voters thought that our ballot paper was not serious, because they did not believe that parties such as 'the Hessian Pirates' or 'the Violets' were real parties. These were the same voters who only minutes before had given the official ballot paper in, with exactly the same names listed upon it.

\subsection{Afterword}

\subsubsection{Repetition of the Election in Hessen}

On January 18th, 2009, the citizens of Hesse were called to vote once again, after the previous elections held 1 year before did not enable state politicians to form a new government.

In the new elections, many of the small parties declined to participate. In total, only ten parties participated: the CDU, the SPD, the Greens, the FDP, the Republican Party, the Civil Liberties Party, the Left, the Free Voters, the NPD, and the 'Hessian Pirates'.

At the state level, the results were a disaster for the socialist party, whose previous main candidate, Andrea Ypsilanti, had infuriated supporters by attempting to form a coalition government with the radical-left "The Left". ${ }^{10}$ As commented above, our

\footnotetext{
${ }^{10}$ Shortly after the election, Miss Ypsilanti took responsibility for the disastrous outcome and retired from her position as Chairman of the SPD in Hesse.
} 
data shows that (at least in Messel), although most Left-supporters approved of the SPD, few of the SPD-supporters approved of the Left, and hence the problems faced by Miss Ypsilanti are hardly surprising. The following table shows the broad results in Hesse and in Messel, where the $\triangle 2008$ columns denote the change in percentage compared to the 2008 election: ${ }^{11}$

\begin{tabular}{lcccc}
\hline Party & \% in Hesse & $\triangle 2008(\%)$ & $\%$ in Messel & $\triangle 2008(\%)$ \\
\hline CDU & 37.2 & +0.4 & 36.4 & +0.2 \\
SPD & 23.7 & -13.0 & 23.5 & -15.3 \\
FDP & 16.2 & +6.8 & 16.4 & +7.4 \\
The greens & 13.7 & +6.2 & 15.0 & +7.9 \\
The left & 5.4 & +0.3 & 4.9 & +0.3 \\
The free voters & 1.6 & +0.7 & 1.6 & +1.1 \\
NPD & 0.9 & 0.0 & 1.0 & +0.1 \\
Rebublican party & 0.6 & -0.4 & 0.4 & -0.5 \\
The hessian pirates & 0.5 & +0.2 & 0.6 & +0.3 \\
Civil liberties party & 0.2 & +0.2 & 0.1 & +0.1 \\
Total & 100.0 & +1.4 & 100.0 & +1.6 \\
\hline
\end{tabular}

Statewide, as well as in Messel, the CDU received the greatest share of votes. With an absolute majority of seats in parliament, together with FDP, the CDU formed the new state government. The picture of the vote in Messel reflects, apart from minor differences, the outcome we observe at state level quite well. The SPD voters punished their party for the attempt, against the promise in pre-election period not to do so, to form a minority government with the backing of the Left. Whilst the share of the CDU and the Left nearly stayed constant, the FDP, the Greens and the Free Voters roughly doubled their share of votes (from the participating parties, the latter three exhibit the largest multiplying factor in our experiment, see above).

Although one should be careful with the interpretation, a notable fact is that the considerable loss of votes suffered by the German Socialist Party in terms of share, both for Hesse and Messel, approximately equals the gain received by the FDP and the Greens. Excluding the possibility of fuzzy preference reversals among the whole population of Hesse, the most plausible and nearest interpretation is that a large fraction voters turned their back on the SPD and, instead, voted for the FDP and the Greens. In the context of our experiment, this development seems very natural. Not only did our experiment show that the Liberals and the Greens share a much higher acceptance rate amongst the population than the official vote suggests, they

\footnotetext{
${ }^{11}$ With only ten parties participating in the election in 2009, the changes of percentages do not add up to $0 \%$, but, with $1.4 \%$ in Hesse and $1.6 \%$ in Messel, represent the total share of votes from 2008 cast for the seven parties that declined to participate.
} 
are also the parties our participants simultaneously approved of with SPD the most (see coalition table).

\subsubsection{A Second Experiment in Germany}

On September 27th, 2009, we conducted a similar experiment during the nationwide German Federal elections (see Alós-Ferrer and Granić 2010 for details). This time, we selected six voting stations in the city of Konstanz, in the southern German state of Baden-Württemberg. Of the 2,879 voters who showed up at the voting stations, $1,431(49.7 \%)$ took part in our study. The overall conclusions with regard to feasibility of the field experiment and voter acceptance were similar to our study in Hessen.

Remarkably, however, in our Konstanz study the results of the approval vote showed major differences from those of the official vote. As in Konstanz itself and most of Germany, the conservative party (CDU) received the simple majority both for the district election ("Erststimme"), where again a single candidate is selected, and the party-list election ("Zweitstimme"), where a party is elected. In contrast, the Green Party would have won both elections under approval voting (at least in the subset represented by the six selected voting stations). ${ }^{12}$ The Green Party was approved by a $58.1 \%$ of the participants, and it was the only party to receive an absolute majority of approvals. The normalized approval vote share of the Green Party was $22.7 \%$, coming before the CDU (16.2\%) and the SPD (18.5\%). In the official vote (restricted to our six voting stations), a vote share of $20.1 \%$ resulted in the Green Party coming in third, after CDU (28.6\%) and SPD (21.9\%). The situation was quite similar for the candidate vote.

The main political observations were also similar to the ones from the Hesse study, with four big parties arising rather than two, and some surprises among allegedly small parties. As an anecdote, the "Pirate Party" was approved of by $20.8 \%$ of the voters (normalized approval share of $8.1 \%$, coming even before The Left), even though the official vote resulted in a vote share of only $3.7 \%$. Other small parties also experienced large boosts, as e.g. the Animal Protection Party.

\subsubsection{Final Words}

Based on the observations above and our overall experience, we would like to argue that our field experiment has shown that, first, Approval Voting is a practicable method which can be easily implemented in practice, and, second, that the data

\footnotetext{
${ }^{12}$ Konstanz, a University city, is of course not representative for Germany. What we find interesting is the difference in results between the approval voting method and the official one.
} 
generated by this method provide a better picture of the political preferences of the electorate than currently used methods.

\section{References}

Alós-Ferrer, C. (2006). A simple characterization of approval voting. Social Choice and Welfare, 27(3), 621-625.

Alós-Ferrer, C., \& Granić, Đ.-G. (2010). Two field experiments on approval voting in Germany. mimeo.

Brams, S. J., \& Fishburn, P. C. (1978). Approval voting. American Political Science Review, 72, 831-847.

Brams, S. J., \& Fishburn, P. C. (2005). Going from theory to practice: the mixed success of approval voting. Social Choice and Welfare, 25, 457-474.

Fishburn, P. C. (1978a). Axioms for approval voting: direct proof. Journal of Economic Theory, $19,180-185$.

Fishburn, P. C. (1978b). Symmetric and consistent aggregation with dichotomous voting. In J.-J. Laffont (Ed.), Aggregation and revelation of preferences. Amsterdam: North Holland.

Laslier, J.-F (2006) Spatial approval voting. Political Analysis, 14(2), 160-185.

Laslier, J.-F., \& Van der Straeten, K. (2004). Une expérience de vote par assentiment lors de l'élection présidentielle de 2002. Revue Française de Science Politique, 54, 99-130.

Laslier, J.-F., \& Van der Straeten, K. (2008). A live experiment on approval voting. Experimental Economics, 11, 97-105. 